\title{
Oesophageal diverticula: principles of management and appraisal of classification
}

\author{
JOHN BORRIE AND ROGER L K WILSON
}

From the Department of Surgery, University of Otago Medical School and Southern Regional Thoracic Surgical Unit, Dunedin, New Zealand

ABSTRACT In this paper we review a consecutive series of 50 oesophageal diverticula, appraise clinical features and methods of management, and suggest an improvement on the World Health Organisation classification. The link between oesophageal diverticula and motor disorders as assessed by oesophageal manometry is stressed. It is necessary to correct the functional disorder as well as the diverticulum if it is causing symptoms. A revised classification could be as follows: congenital-single or multiple; acquired-single (cricopharyngeal, mid-oesophageal, epiphrenic other) or multiple (for example, when cricopharyngeal and mid-oesophageal present together, or when there is intramural diverticulosis).

The World Health Organisation Manual of the International Statistical Classification of Diseases, Injuries, and Causes of Death ${ }^{1}$ currently classifies oesophageal diverticula as follows:

$\begin{array}{cl}\text { Congenital 750.4 } & \text { Acquired } 530.6 \\ \text { Diverticulum: } & \text { Epiphrenic } \\ \text { oesophagus } & \text { Pulsion } \\ \text { pharynx } & \text { Traction } \\ & \text { Zenker's }\end{array}$

In this paper we review 50 consecutive oesophageal diverticula, appraise methods of management, and suggest an expanded classification.

Table 1 Classification of diverticula (50 cases)

\begin{tabular}{lc}
\hline Classification & $\begin{array}{c}\text { Number } \\
\text { of cases }\end{array}$ \\
\hline Congenital mid-oesophageal diverticulum associated & \\
with H-shaped tracheo-oesophageal fistula & 1 \\
Congenital multiple oesophageal diverticula & 1 \\
2 Acquired cricopharyngeal & 37 \\
$\quad$ mid-oesophageal & 5 \\
3 Intrainural diverticulosis & 4 \\
& 2 \\
& 50 \\
\hline
\end{tabular}

Read at the Fiftieth Jubilee Meeting of the Royal Australasian College of Surgeons, Rotorua, New Zealand, August 1977.

Address for reprint requests: Professor John Borrie, University of Otago Medical School, Box 913, Dunedin, New Zealand.

\section{Clinical and functional features and management}

CONGENITAL OESOPHAGEAL DIVERTICULA

Congenital mid-oesophageal diverticulum and $H$-shaped tracheo-oesophageal fistula

Case report A boy aged 11 years had had choking attacks with meals from birth. As he grew, these attacks lessened. Barium swallows in 1946 and 1952 showed a posterior beak-shaped diverticulum $1 \mathrm{~cm}$ above the tracheal bifurcation, and an anterior communication between the oesophagus and trachea (fig 1). Oesophagoscopy revealed a diverticular orifice opening dorsally $20 \mathrm{~cm}$ from the upper jaw, and tapering to a point $3.5 \mathrm{~cm}$ from its origin. The distal oesophagus and hiatus were normal. Because symptoms continued resection was advised.

Through a right thoracotomy, the azygos vein was divided, and the oesophagus raised on a sling. The diverticulum was identified, its base vertically incised and the oesophageal lumen opened. Across the lumen, the fistula $(3 \mathrm{~mm}$ long and $3.5 \mathrm{~mm}$ wide) leading ventrally into the trachea was resected and its oesophageal and tracheal openings closed with fine silk sutures $(3-0)$. The diverticulum was next excised and the mucosal and muscle layers closed. The patient recovered fully. ${ }^{2}$

This dorsal mid-oesophageal diverticulum found in one so young is probably congenital in origin. It could represent a variation of "oesophageal duplication" whereby the duplicated 


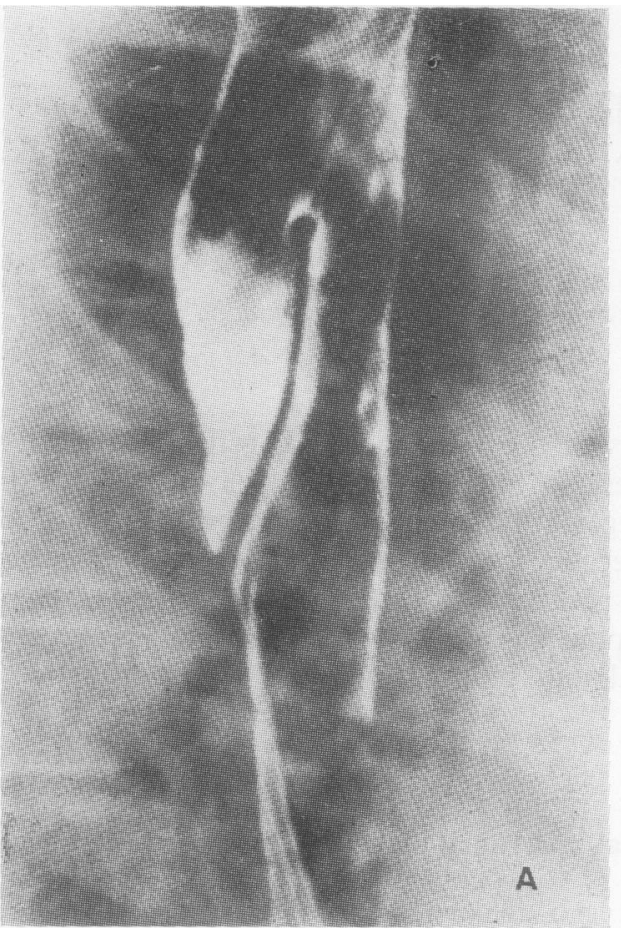

segment, starting within the oesophageal lumen, extended down dorsal and parallel to the normal oesophagus. Johnstone ${ }^{3}$ reported two pseudoduplications. One had a long tubular structure running parallel to the oesophagus with a small opening in the post-cricoid area, ending two inches below the pulmonary artery. The second was shorter and lay close to the tracheal bifurcation. However, this is the reverse of the experience of Gross $^{4}$ with true duplications and of one of us, who reported such duplications starting in the duodenum or jejunum and backtracking through the diaphragm to end blindly in the posterior mediastinum or as high as the sixth cervical vertebra. ${ }^{5}$

\section{Congenital multiple oesophageal diverticula}

Case report A man aged 43 and weighing 80 $\mathrm{kg}$ in 1960, complained of 10 years' flatulence and indigestion. He had a small transient sliding hiatal hernia seen only in barium swallows in 1966 and 1971. After a $10 \mathrm{~kg}$ weight reduction all symptoms disappeared. Manometric studies in 1974 showed no oesophageal or hiatal motor disorder, and no permanent hiatal hernia was seen in barium swallows.

However, the barium swallows in 1960,1963 ,

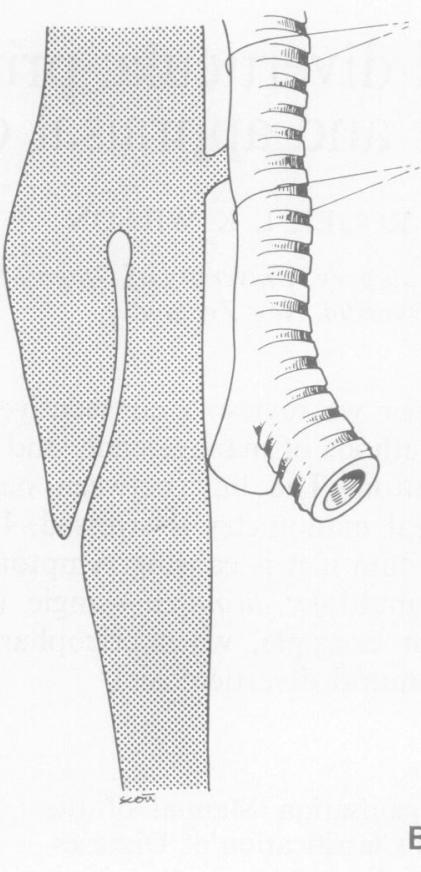

Fig 1 (A) Right lateral view of bariuns swallow showing the $\vec{x}$ diverticulum arising of $2 \mathrm{~cm}$ above tracheal $\vec{\circ}$ bifurcation.

(B) Diagram also showing fistula leading forward into trachea.

1966, 1971, and 1974 all showed three small constant mid-oesophageal diverticula, $1.5 \mathrm{~cm}$ 윽 long and $1 \mathrm{~cm}$ wide which remained constant in size and shape (fig 2). Oesophagoscopy in 1963 and 1971 showed them at 18,23 , and $24 \mathrm{~cm}$ from the upper jaw. They were lined by normalo stratified squamous oesophageal mucosa. Today these transmural pouchings still remain, and areostill symptomless.

These diverticula have not altered in size or shape over a period of 19 years. They are not₹ associated with any oesophageal motor disorders 0 They are therefore considered to be congenita in origin, and they require no treatment.

\section{ACQUIRED OESOPHAGEAL DIVERTICULA}

Cricopharyngeal diverticula

These, the most common variety, occurred in $37 \mathrm{~W}$ patients as mucosal out-pouchings between theo oblique and transverse fibres of the pharyngealo inferior constrictor muscle. There were 23 men and 14 women, whose ages ranged from 49 to $\stackrel{\text { ? }}{?}$ 84 years with a mean of 69 years. The meanto duration of symptoms before seeking medicalo help was 5.5 years; one woman endured symp-尽 toms for 18 years.

Physical signs were minimal but three patients 


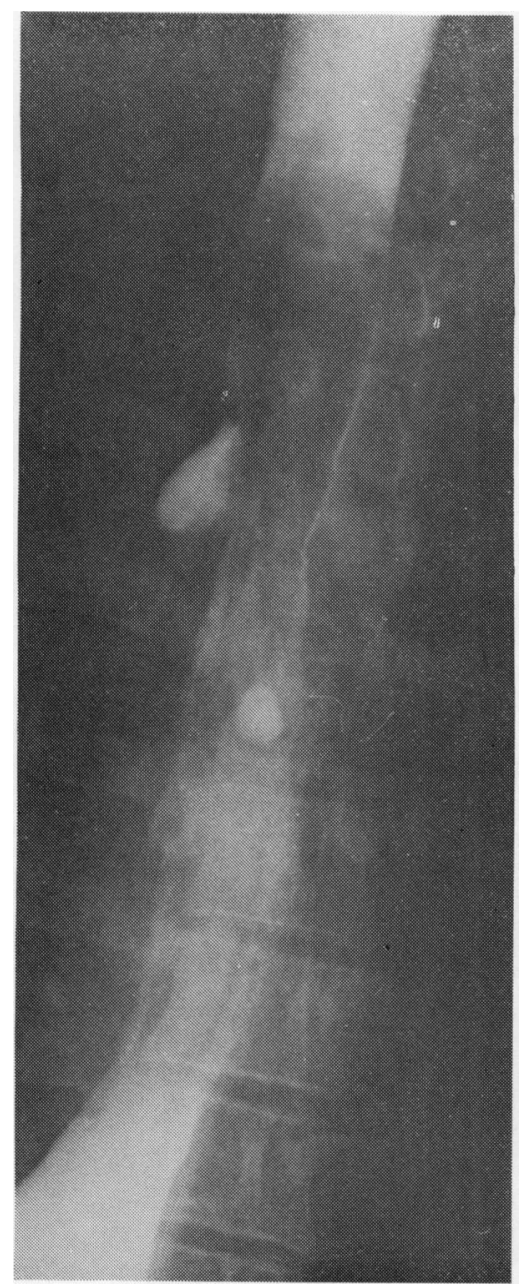

Fig 2 Barium swallow showing the three small transmural diverticula arising at 18, 23, and $24 \mathrm{~cm}$ from upper jaw.

Table 2 Summary of symptoms

\begin{tabular}{ll}
\hline Symptom & Number of cases \\
\hline Dysphagia & 35 \\
Cough and choking & 14 \\
Regurgitation & 12 \\
Retrosternal pain & 3 \\
Gurgling in neck & 2 \\
\hline
\end{tabular}

had weight loss of up to $2 \mathrm{~kg}$, one a non-tender left-sided cervical lump, and one had tracheal deviation.

All patients had lung fluoroscopy and barium swallows. Oesophagoscopy was not done in three who had severe kyphosis, oesophageal dis- placement, and oesophageal occlusion from the diverticulum. Cricopharyngeal pressure studies were done on six patients.

Barium swallows revealed that the diverticula varied in size from a small posterior beak just above the cricopharyngeal sphincter to a long sac $4 \times 8 \mathrm{~cm}$ that filled the thoracic inlet and extended down to the aortic arch. Another, causing total oesophageal obstruction, required emergency excision to restore foregut patency. Foregut occlusion inevitably led to pulmonary infection that in one patient caused an aspiration abscess in the posterior segment of the right upper lobe (fig 3).

Smiley et $\mathrm{al}^{6}$ stressed the link between cricopharyngeal diverticula and hiatal hernias. Sliding hiatal hernias were demonstrated in half the patients-19 in all (fig 4). The reflux oesophagitis in one patient progressed to a severe oesophageal stricture (fig 5) which, failing to respond to dilatation, necessitated oesophago-jejuno-gastrostomy.

Oesophagoscopy showed that the diverticula when small were lined with healthy mucous membrane. When the diverticulum was large, the mucosa became ulcerated from food stasis. None became neoplastic in this series.

The six patients studied manometrically ${ }^{7}$ showed a premature relaxation of the upper oesophageal (cricopharyngeal) sphincter and a post-relaxation sphincteric contraction at the time when pharyngeal contraction was taking place above. This motor incoordination created a physiological obstruction at the upper oesophageal sphincter so that high pressures were built up within the pharynx, conductive to herniation of pharyngeal mucosa through weak areas in the pharyngeal wall.

In managing such cases the decisions relate to (1) the cricopharyngeal diverticulum, and (2) the hiatal hernia-is it causing symptoms? Is there reflux oesophagitis? Is there irreversible oesophageal stenosis?

In 1950 Negus $^{8}$ reported diverticular recurrence after simple pouch excision. In 1969 Ellis $^{9}$ showed the importance of cricopharyngeal myotomy when surgically treating pharyngo-oesophageal diverticula. The above-mentioned manometric studies on our group revealed the reason why. The fast-moving tracing used by Lichter on these patients showed that the phase of cricopharyngeal relaxation had passed by the time the incoordinate peristaltic wave down the pharynx reached this level. When cricopharyngeal incoordination is shown manometrically, cricopharyingeal myotomy is needed, as well as a decision whether to excise the diverticulum. 


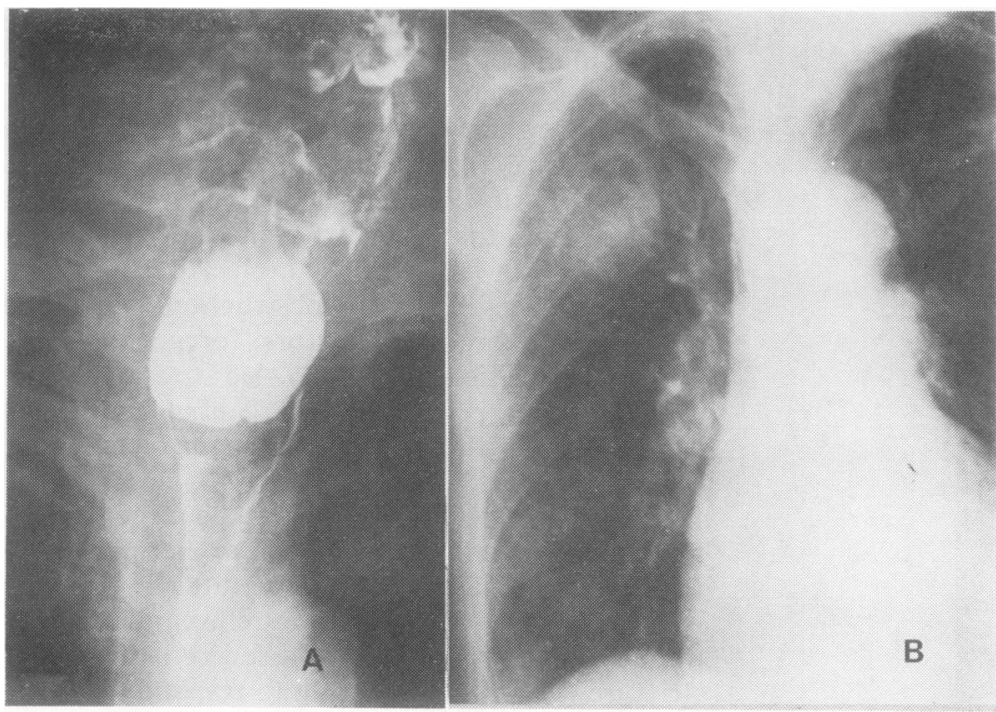

Fig 3 Larger cricopharyngea $\overrightarrow{\vec{F}^{2}}$ diverticulum and associated $\dot{\omega}$ right upper lobe lung abscess:

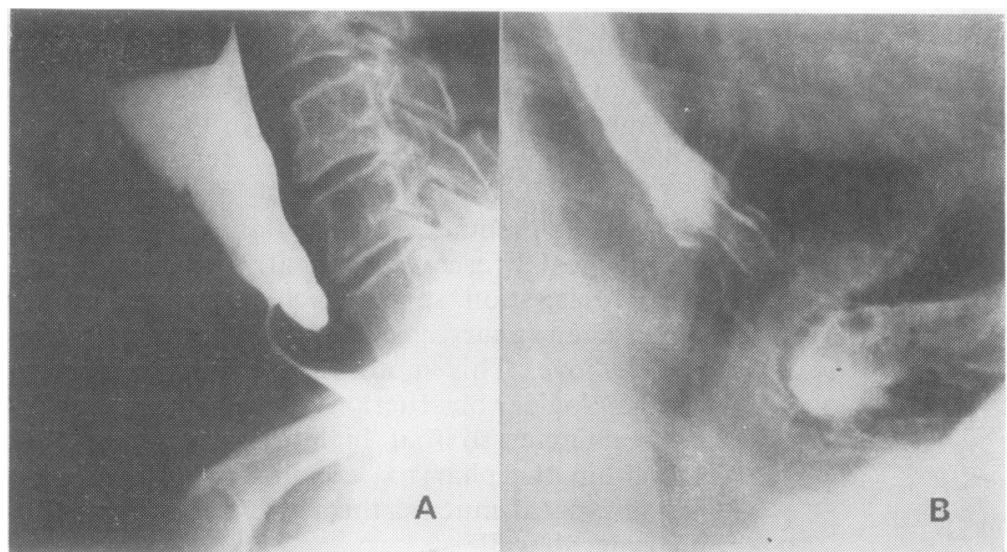

Fig 4 Small cricopharyngeal diverticulum and associated sliding hiatal hernia.

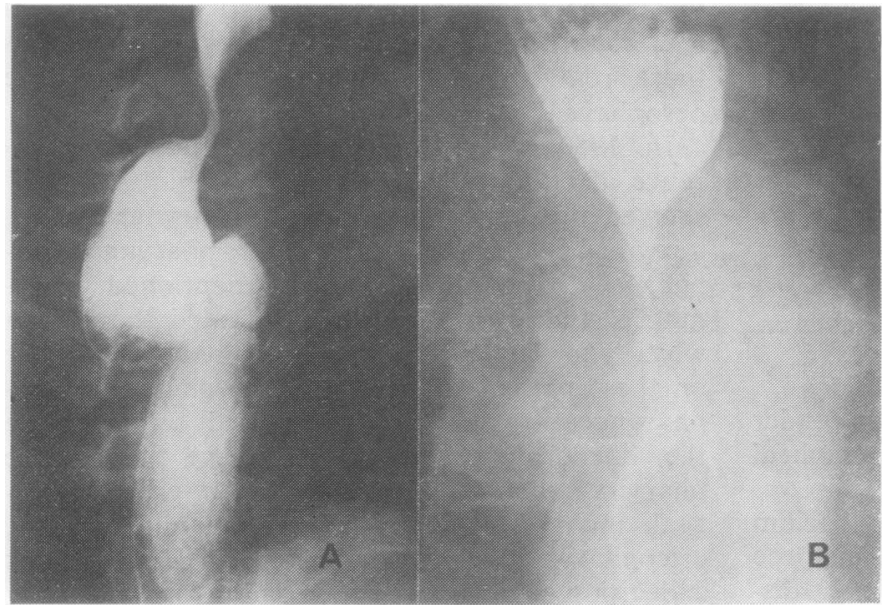

Fig 5 Large cricopharyngeal diverticulum and associated transmural oesophagitis with tight hiatal stricture. 
In our experience all "beak-pouches" $1 \mathrm{~cm}$ or less long with symptoms need cricopharyngeal myotomy only. However, large diverticula causing progressive dysphagia need excision and vertical cricopharyngeal myotomy, best performed when a wide-bore stomach tube (35F) has been slid temporarily down the oesophagus for intraluminal support during the procedure. The surgical approach is along the anterior border of the sternomastoid muscle.

Because of their trivial symptoms, all but one of the hiatal hernias were treated by medical means alone. However, one 80-year-old man who had undergone pouch excision later required an oesophago-jejuno-gastrostomy for the treatment of a lower oesophageal stricture which did not respond to repeated dilatation.

Those who had no treatment other than oesophagoscopy were swallowing satisfactorily. All three patients who had myotomy alone were swallowing normally between three and five years after operation. Of 18 patients treated by diverticular excision, the longest postoperative follow-up was 20 years and the shortest two years with no recurrence of symptoms. Of five patients who had excision and myotomy, four were well. The fifth developed symptoms of hiatal hernia after five years without any recurrence of cervical symptoms.

\section{Mid-oesophageal diverticula}

Ever since the early descriptions of Rokitansky, in 1840, Zenker in 1878, ${ }^{11}$ and Kragh in 1932,12 these have been called "traction" diverticula. This was based on the findings of adhesions linking the diverticulum to mediastinal lymph nodes that had undergone the pathological changes of anthracosis or tuberculosis. Ribbert, 1314 however, contested this view, strongly supporting a congenital basis for such lesions.

That oesophageal motor dysfunction could be the true basis for such diverticula was suggested by D'Abreu ${ }^{15}$ in 1949, and confirmed manometrically by Gross et al in $1961 .^{16}$ More recently

Table 3 Summary of treatment for pharyngeal diverticula

\begin{tabular}{lcc}
\hline Treatment: & Number of cases \\
\hline $\begin{array}{l}\text { Oesophagoscopy alone } \\
\begin{array}{l}\text { Operation } \\
\text { Myotomy alone }\end{array}\end{array}$ & 11 \\
$\begin{array}{l}\text { Diverticular excision } \\
\text { Diverticular excision } \\
\text { + myotomy }\end{array}$ & 3 & 26 \\
$\quad$ Total & 18 & \\
$\quad$ & 5 & -37 \\
\hline
\end{tabular}

$\mathrm{Kaye}^{17}$ found gross oesophageal motor dysfunction in 12 patients whose diverticulum was immediately beyond the tracheal bifurcation, at the classic "traction diverticulum" site-only one patient had any radiological evidence of previous pulmonary tuberculosis.

We had five patients with mid-oesophageal diverticula, four with manometrically proven motor disorders (fig 6A). One diverticulum causing symptoms was resected (fig 6B). There was nothing in any of these patients with midoesophageal diverticula to indicate at any time that they had had tuberculous infection of lungs, mediastinum, or elsewhere. There was no radiological evidence of lung or mediastinal calcification. No "past history" in any way suggested that any of these patients had at any time suffered from tuberculosis.

On the other hand, four did have proven motor disorders. The one that was treated surgically had no strands of fibrous tissue coming from the diverticulum and leading to any mediastinal lymph nodes. The diverticulum was a vertical "out-pouching" of mucous membrane through the muscle wall of the oesophagus.

All the available evidence suggests that in western societies in this century the most common cause of these diverticula is an oesophageal motor disorder, not tuberculosis. We believe that if dysphagia is present, its cause must be found and corrected; if it is not these diverticula can be ignored. We have not seen them become neoplastic.

\section{Epiphrenic diverticula}

These, comprising less than $10 \%$ of all oesophageal diverticula, ${ }^{18}$ were ascribed by Mondière $^{19}$ in 1833 to increased intraluminal pressure. In $1953 \mathrm{Kay}^{20}$ reported muscular hypertrophy immediately below such diverticula, and Effler et $a^{21}$ describing seven patients, confirmed the presence of consistent hypertrophy of the circular muscle of the terminal oesophagus. One may thus expect the lesion with cardiospasm, diffuse lower oesophageal spasm, and hiatal hernia. In our group there were four patients, three with hiatal hernias, and one with cardiospasm. Symptoms are usually those of the cause, rarely the diverticulum per se.

This link with disordered oesophageal motility again underlines Effler's view, ${ }^{21}$ that it is pointless to treat the diverticulum without also correcting the cause of the motor disorder. Lower oesophageal function must be investigated by barium swallow and manometry, and by $\mathrm{pH}$ studies to 


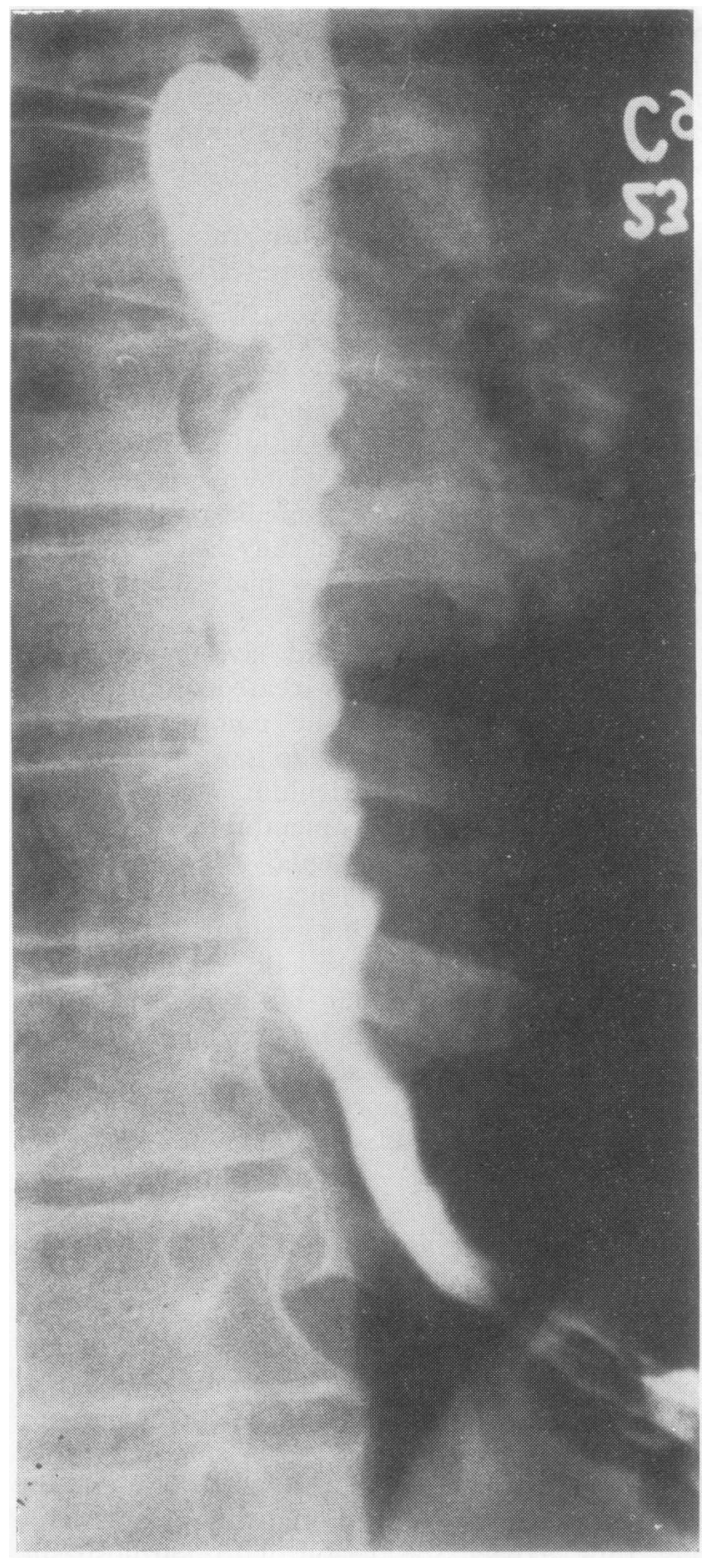

A intake, stopping smoking, taking antacids, and sleeping with the bed-head raised. In two this relieved symptoms which were indeed those of the hiatal hernia (fig 7A).

When medical treatment fails, the patient is

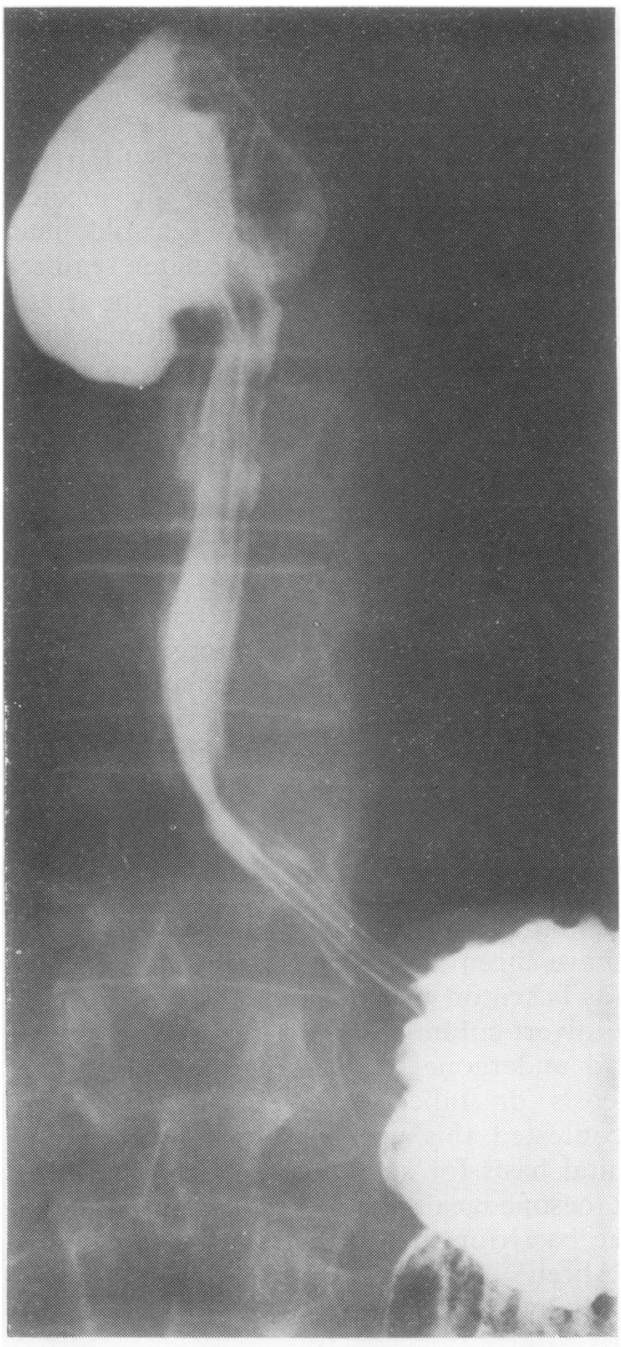

B

Fig 6 (A) Symptomless mid-oesophagea.' diverticulum above a lower oesophageal diffuse muscle spasm. (B) Right antero-lateral mid-oesophageal diverticulum in 54-year-old man with a two-year history of increasing dysphagia: no motor disorder shown in motility studies.

measure gastric reflux. ${ }^{22}$

Treatment depends on the findings. Those patients with hiatal hernias and accompanying obesity are first treated medically by bland diet, weight reduction including reduced alcohol operated on via a left thoracotomy. The diverti culum is excised, the oesophageal mucosa an musculature repaired, an extended oesophago cardiomyotomy made, and the associated hiata hernia repaired ${ }^{21}$ (fig 7B). 


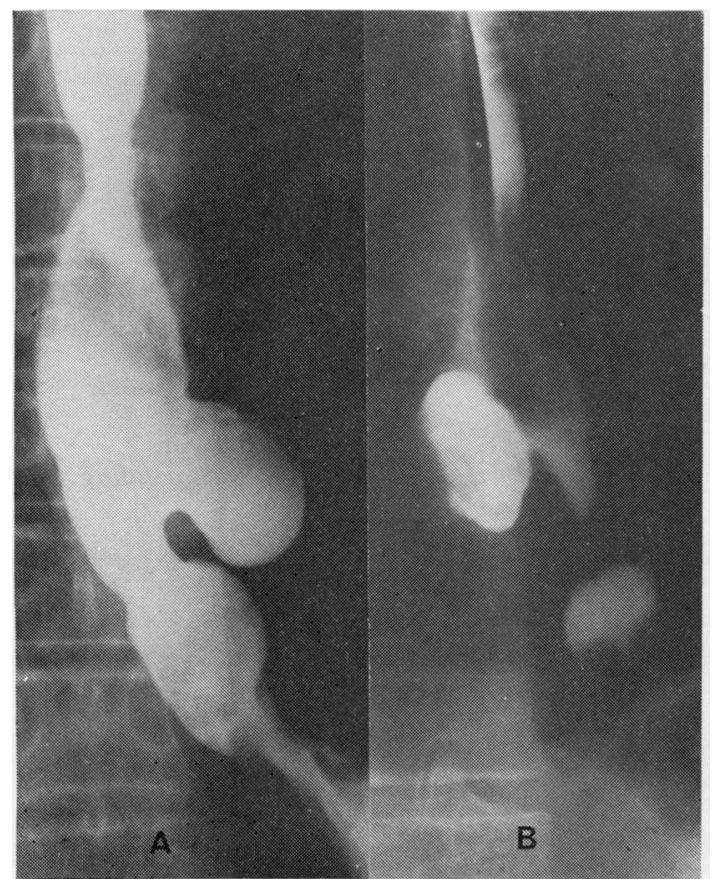

Fig 7 (A) Large epiphrenic aiverticulum above a sliding hiatal hernia in a 54-year-old man weighing $109 \mathrm{~kg}$. He was treated medically by weight reduction to $80 \mathrm{~kg}$ and cessation of smoking with resolution of symptoms. (B) Epiphrenic diverticulum above a hiatal hernia treated by the Effler technique of diverticular excision, cardiomyotomy, and hiatal herniolrhaphy.

OESOPHAGEAL INTRAMURAL DIVERTICULOSIS First described in 1960 by Mendl et al, ${ }^{23} 24$ this condition occurred in two patients.

\section{Case reports}

Case 1 This man (RS), aged 65 years, referred in April 1971 with dysphagia, was shown by barium swallow and oesophagoscopy to have a sliding hiatal hernia and a mucosal stricture at $35 \mathrm{~cm}$ from the upper jaw. The stricture lumen was $14 \mathrm{~F}$. He was treated medically until 26 October 1972, when because of continued symptoms he had a hiatal herniorrhaphy and dilatation of the stricture. Though he improved for a year, his dysphagia returned. A barium swallow in May 1974 showed oesophageal neuromuscular incoordination without evidence of stricture. At this examination numerous small mucosal diverticula were noted along the lower oesophagus. Review of the earlier films showed that though the diverticula had been present in small numbers in 1972, in the next two years they had become more numerous.
Case 2 This 64-year-old man (RJWB), while convalescing from multiple trauma including a fractured pelvis and urethra, gave a two-month history of dysphagia and vomiting. A barium swallow showed a sliding hiatal hernia and also multiple intramural diverticula in the lower third of the oesophagus (fig 8). The hernia, being entirely incidental to his multiple injuries, was treated medically.

The intramural diverticula, symptomless in themselves, were incidental to the underlying hiatal hernia, and were ignored.

\section{Appraisal of classification}

Classifying disease is not easy, but we believe the current published classification of oesophageal diverticula is inadequate. At best it is all-inclusive and multi-based on site, function, and eponymsfor example, "epiphrenic, pulsion, and Zenker's," without any central logical common theme.

The concept of "traction," popular a century ago and pleasant for teaching surgical concepts, is no longer tenable. Does fibrous tissue really cause lateral traction diverticula? We have been unable to demonstrate this phenomenon, nor were any of our cases associated with mediastinal fibrotic lesions. We support Ribbert's rejection of the traction concept. Further, we can add evidence in support of the views of d'Abreu, Cross, and Kaye of the link with motor disorders.

We have confirmed that oesophageal disease such as cricopharyngeal incoordination, lower oesophageal spasm, achalasia, and sliding hiatal hernias have all been associated with proximal oesophageal diverticula, be they cricopharyngeal, mid, or epiphrenic, or indeed intramural diverticulosis.

In our small but varied experience we have confirmed congenital as a valid subgrouping, and we suggest that this should be expanded to include single and multiple varieties. We suggest that in classifying single acquired oesophageal diverticula the best basis is an anatomical onenamely by site-and that the order could be cricopharyngeal, mid-oesophageal, epiphrenic. Multiple diverticula can include the subheading intramural diverticulosis.

In conclusion we suggest the following revised classification: congenital-single or multiple; acquired-single (cricopharyngeal, mid-oesophageal, epiphrenic, other) or multiple (based on single varieties, for example, when cricopharyngeal and mid-oesophageal present together, or when there is intramural diverticulosis). 


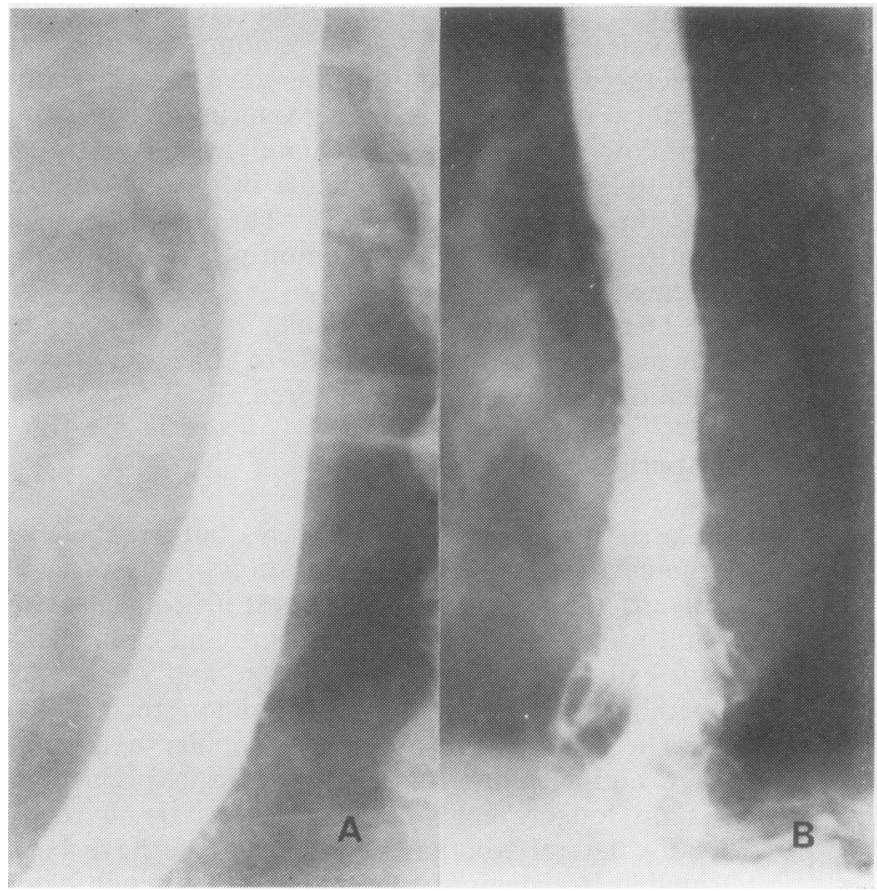

Fig 8 ( $A$ and $B$ ) Intramural diverticulosis associated with sliding hiatal hernia.

\section{References}

1 Manual of the International Statistical Classification of Diseases, Injuries, and Causes of Death, 1975 Revision. Geneva: World Health Organisation, 1977-78: 1:425-6, 2:167.

2 Robb D. Congenital tracheo-oesophageal fistula without atresia but with large oesophageal diverticulum. A ust N Z J Surg 1952; 22:120-2.

3 Johnstone AS. Diverticula of the oesophagus. Br J Radiol 1949; 22:415-22.

4 Gross RE. The surgery of infancy and childhoo!. Philadelphia: WB Saunders, 1953: 221.

5 Borrie J. Duplication of the oesophagus. Review and description of two cases. Br J Surg 1960-61; 48:611-8.

6 Smiley TB, Caves PK, Porter DC. Relationship between posterior pharyngeal pouch and hiatus hernia. Thorax 1970; 25:725-31.

7 Lichter I. Motor disorder in pharyngooesophageal pouch. J Thorac Cardiovasc Surg 1978; 76:272-5.

8 Negus VE. Pharyngeal diverticula. Observations on their evolution and treatment. Br J Surg $1950-51 ; 38: 129-46$.

9 Ellis FH, Schlegel JF, Lynch VP, Payne WS. Crico-pharyngeal myotomy for pharyngooesophageal diverticulum. Ann Surg 1969; 170: 340-9.

10 Rokitansky C. Spindelformige Erweiterung der Speisröhre Mcd Jaltrb drk Österr Staates 21:219,
1840. Cited by Gerard FP, Sabety AM. Pulsion diverticulum of the mid-thoracic oesophagus. Dis Chest 1966; 49:655-7.

11 Zenker FA, von Ziemssen H. Cyclopedia of the practice of medicine. London: Sampsom Low Marston, Searle and Rivington, 1878: 46-89.

12 Kragh J. Tuberculous diverticula of the oeso음 phagus (so-called traction diverticula). Actax Otolaryngol 1922-23; 4:49-62.

13 Ribbert H. Die Traktionsdivertikel des Oeso phagus. Virchows Arch (Pathol Anat) 1904; 178:0ิ $351-67$.

14 Ribbert H. Noch Einmal das Traktionsdivertikelo des Oesophagus. Virchows Arch (Pathol Anat) 1906; 184:403-13.

15 d'Abreu AL. Diverticula of the oesophagus. $B r$ J Radiol 1949; 22:423-6.

16 Cross FS, Johnson GF, Gerein AN. Oesophageat diverticula. Arch Surg 1961; 83:525-33.

17 Kaye MD. Oesophageal motor dysfunction in patients with diverticula of the mid-thoracico oesophagus. Thorax 1974; 29:666-72.

18 Terracol J, Sweet RH. Diseases of the oesophagus. Philadelphia: WB Saunders, 1958:C 264-71.

19 Mondière JT. Cited by Harrington SW. The surgical treatment of pulsion diverticula of the thoracic oesophagus. Ann Surg 1949; 129:606-18. $\frac{\varrho}{\circ}$

20 Kay EB. The inferior oesophageal constrictor in relation to lower oesophageal disease. $J$ Thorac Surg 1953; 25:1-13.

21 Effler DB, Barr D, Groves LK. Epiphrenic diver= 
ticulum of the oesophagus. Arch Surg 1959; 79: 459-67.

22 Lichter I. Measurement of gastro-oesophageal acid reflux: its significance in hiatus hernia. $\mathrm{Br} \mathrm{J}$ Surg 1974; 61:253-8.

23 Mendl K, McKay JM, Tanner CH. Intramural diverticulosis of the oesophagus and RokitanskyAschoff sinus in the gall bladder. $\mathrm{Br} J$ Radiol 1960; 33:496-501.

24 Montgomery RD, Mendl K, Stephenson SF. Intramural diverticulosis of the oesophagus. Thorax 1975; 30:278-84. 